\section{Estudo \\ CoDebate}

em Testão

Plamejamento
Revista Estudo \& Debate, Lajeado, v. 23, n. 2, 2016. ISSN 1983-036X

DOI: http://dx.doi.org/10.22410/issn.1983-036X.v23i2a2016.1058

\title{
FINANÇAS COMPORTAMENTAIS: UM ESTUDO DO PERFIL DE INVESTIDORES DE AGÊNCIAS BANCÁRIAS DO MUNICÍPIO DE PORTO ALEGRE/RS
}

\author{
Arthur Gehrke Martins Andrade ${ }^{1}$, Carlos Artur dos Santos Lencini², André Kohl ${ }^{3}$
}

\begin{abstract}
Resumo: A interferência de vieses comportamentais e emocionais nas decisóes financeiras tomadas pelos indivíduos é o foco principal de um novo campo de pesquisa denominado finanças comportamentais, o qual busca entender os mecanismos utilizados no processo de tomada de decisão destes indivíduos. Este artigo se propôs a pesquisar a tomada de decisão de investidores financeiros e seu comportamento, para entáo descrever o seu perfil. Para isso foi realizada uma pesquisa quantitativa, na qual foram entrevistados cem investidores de seis instituições bancárias diferentes, escolhidos por conveniência. Por meio da análise destas informaçôes coletadas junto aos investidores pesquisados foi possível identificar os entrevistados que apresentaram um comportamento conservador, preferindo proteger seu capital com investimentos em ativos de renda fixa ao invés de arriscar com ativos de renda variável, e aqueles investidores com perfil moderado ou arrojado.
\end{abstract}

Palavras-chave: Finanças comportamentais. Tomada de decisão. Investimentos financeiros. Perfil de investidores.

\section{BEHAVIORAL FINANCE: A STUDY ON THE PROFILE OF INVESTORS OF BANK BRANCHES IN THE MUNICIPALITY OF PORTO ALEGRE/RS}

\begin{abstract}
The interference of behavioral and emotional biases in financial decisions made by individuals is the main focus of a new research field called behavioral finance, which seeks to understand the mechanisms used in the decision-making process of these individuals. This article aimed to investigate the decision-making of financial investors and their behavior, and then describe their profile. In order to do that, a quantitative survey was carried out, in which a hundred investors were interviewed from six different banks, chosen by convenience. Through the analysis of the information collected from the surveyed investors, it was possible to identify the interviewees who had a conservative behavior, preferring to protect their capital by investing in fixed income assets rather than taking risks in variable income assets, and those investors with moderate or bold profile.
\end{abstract}

Keywords: Behavioral Finance. Decision making. Financial Investment. Investors profile.

1 Graduado em Administração. Centro Universitário Metodista - IPA - RS / Brasil.

2 Professor Mestre do Curso de Administração. Centro Universitário Metodista - IPA - RS / Brasil.

3 Professor Mestre do Curso de Administração. Centro Universitário Metodista - IPA - RS / Brasil. 


\section{INTRODUÇÁO}

Umas das primeiras teorias do campo das finanças, a teoria tradicional, buscava entender as decisões financeiras e o próprio mercado financeiro, baseando-se em modelos apoiados na premissa de que os agentes eram perfeitamente racionais (LUCCHESI, 2010), desconsiderando, assim, os fatores psicológicos envolvidos no processo de tomada de decisão por parte destes agentes (ANACHE; LAURENCEL, 2013).

Lucchesi (2010), afirma ainda que os questionamentos gerados em torno das primeiras teorias das finanças proporcionaram o entendimento de que o processo decisório dos indivíduos é permeado por erros sistemáticos, portanto, as decisóes tomadas por estes agentes não eram baseadas unicamente em mecanismos plenamente racionais. Kahneman (2012) esclarece que estes questionamentos resultaram da influência exercida por outros campos de estudo ligados à psicologia, sociologia e economia.

Como resultado destes questionamentos nasce uma nova linha de pesquisa chamada de finanças comportamentais, a qual busca entender as reaçóes dos indivíduos frente as suas decisôes financeiras, por meio da compreensão da influência de predisposiçôes psicológicas (ASSAF NETO, 2010).

Os estudiosos das finanças comportamentais proporcionaram contribuiçóes relevantes para as teorias de finanças anteriormente vigentes, principalmente nos aspectos que envolvem os investidores, os quais deixaram de ser considerados totalmente racionais, como defendido inicialmente, para serem considerados indivíduos simplesmente normais (HALFELD; TORRES, 2001).

Embora em constante evoluçáo, os estudos referentes às finanças comportamentais carecem ainda de comprovaçôes científicas capazes de propagar o tema para além do âmbito acadêmico, e buscar inserir de forma mais significativa os profissionais de instituiçóes financeiras nessa discussão, a qual envolve diversos fatores presentes em suas atividades.

Muito foi feito no sentido de comprovar a influência de fatores psicológicos que agem sobre os indivíduos durante seu processo de tomada de decisão e na tentativa de expor as limitaçóes das antigas teorias de finanças, assim como inserir aspectos emocionais e irracionais em um campo de estudos até entấo focado na plena racionalidade de seus agentes. Entretanto, ao ter em vista a enorme complexidade e dimensáo do tema - principalmente por tratar do comportamento humano - ainda se tem muito a pesquisar e elaborar a fim de se buscar novos conhecimentos que possam vir a contribuir ainda mais com as atividades dos profissionais do ramo, assim como, com os pesquisadores ligados ao tema.

Com base nessa discussão, este estudo busca pesquisar a tomada de decisão e o comportamento de investidores financeiros de diferentes agências bancárias, visando, por fim, descrever o perfil destes investidores. Para isso, são identificadas as escolhas, percepçóes e expectativas de retorno e risco apresentadas por estes investidores, e o quanto estes fatores interferem em seu processo de tomada de decisão perante os diferentes investimentos financeiros existentes. 


\section{REFERENCIAL TEÓRICO}

Segundo Macedo Junior (2003), é possível dividir as teorias de finanças entre a teoria tradicional de finanças, também chamada de finanças antigas; a teoria moderna de finanças; e por último, e mais recentemente, as finanças comportamentais (behavioral finance).

As finanças antigas preconizavam a decisão da avaliação quanto ao investimento centrada na análise de balanços e demonstraçôes financeiras, portanto tendo como referência a Contabilidade (ANACHE; LAURENCEL, 2013). O foco desta teoria é, principalmente, a formação de carteiras de investimentos capazes de gerar retornos superiores aos índices médios de mercado, portanto, o seu objetivo era obter uma remuneração acima da média do mercado (MACEDO JUNIOR, 2003).

Por sua vez, a teoria moderna de finanças, conforme expóem Anache e Laurencel (2013) possuí como base princípios que defendem que os investidores agem de forma racional e são avessos ao risco e de que o mercado é altamente eficiente. Esta teoria, fundada por Harry Max Markowitz no início dos anos 1950, foi fortemente influenciada pela teoria dos jogos (MACEDO JUNIOR, 2003).

Os questionamentos provenientes das teorias antiga e moderna de finanças, segundo Lucchesi (2010), proporcionaram o surgimento de um novo campo de pesquisa denominado finanças comportamentais. Conforme Halfeld e Torres (2001) esta nova teoria procura aperfeiçoar a teoria moderna de finanças, adicionando fatores comportamentais que interferem no processo de tomada de decisão dos investidores.

Segundo Tversky e Kahneman (1974) as pessoas se apoiam em um número limitado de princípios heurísticos ao realizarem tarefas complexas de avaliar probabilidades e predizer valores, fato este que pode levar a erros graves e sistemáticos. Os autores elencam entáo, três heurísticas empregadas pelos indivíduos nestes momentos de avaliar probabilidades e prever valores, a conhecer: heurística da representatividade; heurística da disponibilidade; e heurística de ajuste e ancoragem.

Macedo Junior (2003) afirma que é possível definir heurística como sendo um conjunto de regras e métodos utilizados na resolução de problemas. Lucchesi (2010) esclarece que de forma diferente, o viés heurístico preconiza que as pessoas cometem erros ao tomarem decisóes, pois essas confiam em regras práticas para processar as informaçóes.

Para Lucchesi (2010), a heurística da representatividade refere-se a julgamentos baseados em estereótipos. Segundo Tversky e Kahneman (1974) as pessoas manifestam grande confiança em suas previsóes baseadas em estereótipos, mesmo que estes estereótipos sejam baseados em descrições escassas e inconfiáveis.

Assim sendo, Macedo Junior, Kolinsky e Morais (2011), concluem que esta heurística pode provocar certas anomalias no mercado financeiro, como por exemplo, a confusão, por parte dos investidores, na diferença entre bons investimentos e boas empresas, os quais nem sempre estão relacionados.

Por outro lado, Kahneman (2012) define que a heurística da disponibilidade é a confiança que as pessoas possuem em puxar algum fato da memória. De acordo com Macedo Junior, Kolinsky e Morais (2011), nesta heurística as pessoas buscam associações 
entre informaçôes que lhes são mais familiares e tendem a se concentrarem em um fato particular ao invés da situação como um todo.

A respeito da heurística da ancoragem, Tversky e Kahneman (1974) indicam que está ligada ao fato de as pessoas ao fazerem alguma estimativa, muitas vezes partirem de um valor inicial. Nessa linha, Anache e Laurencel (2013) apontam que o ponto de partida, também chamado de âncora, pode ser visualizado, por exemplo, em casos de compra e venda de açóes, quando os investidores utilizam como referência algum preço atingido em dada época.

Além destas heurísticas, diversos vieses comportamentais agem, igualmente, no processo de tomada de decisão dos investidores, sendo alguns mais facilmente percebidos, como o excesso de confiança e o otimismo. Ambos estáo ligados ao fato de os investidores muitas vezes subestimarem os riscos envolvidos em suas decisóes (LUCCHESI, 2010).

Macedo Junior, Kolinsky e Morais (2011) citam ainda outras ilusões cognitivas conhecidas como efeito disposiçấo, contabilidade mental, medo do arrependimento, procura do orgulho, entre outras. Todas relacionadas, de forma geral, com o medo que as pessoas possuem de se arrepender e com a vontade de sentirem orgulho.

Semelhante a estes sentimentos, a aversão ao risco, conforme expõe Assaf Neto (2010), deriva do costume dos investidores de darem maior peso à dor da perda do que a satisfação do ganho. Este fenômeno foi estudado por Kahneman e Tversky (1979), os quais apresentam a Teoria da Perspectiva. Conforme Lucchesi (2010), este trabalho permitiu que se chegasse à conclusão de que o aborrecimento relativo à perda de uma soma em dinheiro é geralmente maior do que o prazer associado ao ganho do mesmo montante.

Segundo Kahneman (2012, p. 542) este fenômeno expressa a intuição de que "uma perda de $\$ \mathrm{X}$ é mais aversiva do que um ganho de $\$ \mathrm{X}$ é atraente". Este efeito é representado no gráfico da função hipotética de valor da teoria da perspectiva, conforme demonstrado na Figura 1.

Figura 1 - Função hipotética de valor da teoria da perspectiva de Kahneman e Tversky (1979)

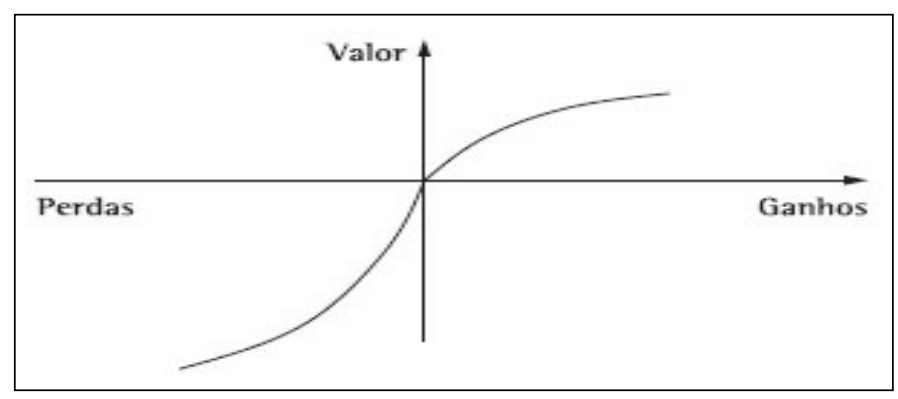

Fonte: Kahneman (2012, p. 542).

Como esclarece Kahneman (2012), a função de valor é definida pelos ganhos e perdas, não importando o fator riqueza total. Pode-se notar que a curva é côncava nos 
ganhos e convexa nas perdas, sendo consideravelmente mais acentuada para as perdas do que para os ganhos.

O nível de aceitação ao risco de perfis diferentes de investidores, conforme argumentam Bodie, Kane e Marcus (2000), interfere nos investimentos escolhidos por estes investidores. Aqueles que possuem maior tolerância ao risco tendem a se concentrar em ativos considerados mais arriscados, como as açóes, e aqueles mais conservadores procurarão investimentos considerados mais seguros.

Croson e Gneezy (2009) destacam que também existem diferenças de perfil e de estratégias de investimento entre investidores de gêneros diferentes, no que se refere ao nível de tolerância para situaçóes de risco e de incertezas. Os homens, diferentemente das mulheres, tendem a apresentar um excesso de confiança que os leva a encarar as situaçóes de risco como uma oportunidade ao contrário de uma ameaça, elevando a sua tolerância a essas situaçôes. Por sua vez, as mulheres possuem uma maior sensibilidade aos sinais sociais, o que torna seu comportamento mais suscetível a variaçóes.

Além das características pessoais do investidor, Damodaran (2006) ressalta que o nível de aceitação ao risco também pode resultar de circunstâncias do mercado e da situação em que o investidor se encontra. Por exemplo, o fato de o investidor possuir um emprego instável, ou de estar próximo da aposentadoria, ou até mesmo, se o mercado estiver em um momento muito especulativo, a aceitação ao risco por parte do investidor tenderá a ser menor.

Especificamente acerca das características do mercado financeiro brasileiro, há uma explicação econômica para que o investidor brasileiro tenha uma percepçáo negativa acerca de investimentos considerados muito voláteis ou arriscados. Tendo em vista a sempre alta taxa de juros no Brasil - antes de 1994 por conta da crescente inflação e, após o Plano Real, pelas limitaçóes estruturais de crescimento da economia - o custo de oportunidade era mais atrativo. Ou seja, se o investidor podia obter um retorno atraente em renda fixa com baixo risco, não havia motivos para o mesmo tolerar as oscilaçóes de qualquer investimento em renda variável, mesmo que essa oscilação fosse favorável (PÓVOA, 2012).

Póvoa (2012), ao analisar o caso de Portugal, Espanha e Grécia, países onde houve uma grande migração de investimentos em renda fixa para renda variável após as respectivas adesões desses ao euro, alega que a mudança de hábito pode ser alcançada mediante estímulos macroeconômicos - através de juros mais baixos e estabilidade econômica - diferentemente da mudança cultural que é algo que pode levar geraçóes para ser alterada.

Diante dessa perspectiva, Kahneman (2012) conclui que muitos problemas de decisão se resumem a uma escolha entre conservar o status quo ou aceitar uma alternativa a ele, o que em alguns aspectos é vantajoso e em outros pode ser desvantajoso.

\section{METODOLOGIA}

Esse estudo caracteriza-se como uma pesquisa quantitativa do tipo descritiva, na qual, segundo Nique e Ladeira (2014), se busca através de objetivos bem claros e definidos, obter detalhes específicos sobre consumidores e seus comportamentos, de forma precisa, visando evitar distorçóes de análises e interpretaçóes. 
Como instrumento de coleta de dados foi utilizado um questionário contendo dezenove perguntas fechadas elaboradas pelo autor com base no estudo da Teoria da Perspectiva de Kahneman e Tversky (1979), apresentado no referencial teórico. Este instrumento passou por um pré-teste realizado com uma amostra de dez investidores escolhidos por conveniência pelo autor. Os investidores abordados foram questionados pessoalmente acerca de possíveis dificuldades de entendimento das questóes apresentadas; acerca da extensão do questionário; e quanto a possíveis sugestôes.

Após a finalização dos ajustes necessários no questionário, deu-se início a etapa de coleta de dados, realizada durante os meses de Julho e Agosto do ano de 2015. Foram entrevistados cem investidores, clientes de seis agências bancárias pertencentes a diferentes instituições financeiras localizadas no bairro Rio Branco, no município de Porto Alegre, no estado do Rio Grande do Sul.

A amostragem se deu por conveniência, uma vez que o critério utilizado na escolha das agências pesquisadas foi a sua localização - sendo selecionadas aquelas que estavam mais facilmente ao alcance do pesquisador e que autorizaram a realização da pesquisa. Por sua vez, o número de entrevistados em cada instituição foi estipulado junto aos gestores de cada agência, de acordo com a viabilidade de se aplicar os questionários somente em clientes pessoa física da agência pesquisada; investidores de algum ativo financeiro; e que apresentassem interesse em participar da pesquisa.

Tendo em vista esses critérios adotados, se alcançou um total de cem entrevistados de diferentes instituiçóes, divididos de maneira não uniforme, da seguinte forma: catorze questionários no Banco A (privado); quatro questionários no Banco B (privado); quinze questionários no Banco $\mathrm{C}$ (público federal); vinte e cinco questionários no Banco $\mathrm{D}$ (público federal); trinta e dois questionários no Banco $\mathrm{E}$ (público estadual); e por último, dez questionários no Banco $\mathrm{F}$ (privado).

Os dados obtidos foram analisados através da análise estatística descritiva que segundo Collis e Hussey (2005), além de descrever os dados, também é útil para resumir os dados em tabelas, quadros e gráficos. Em razão de a presente pesquisa náo possuir uma amostragem uniforme, com o mesmo número de investidores entrevistados entre as diferentes instituiçóes financeiras pesquisadas, os dados foram todos reunidos e analisados sob a mesma perspectiva. Este fato impossibilitou a realização de uma comparação e de uma análise mais aprofundada entre o comportamento e o perfil dos entrevistados de diferentes agências.

\section{RESULTADOS}

Visando identificar as escolhas dos investidores pesquisados perante algumas alternativas de ativos financeiros disponibilizados no mercado, estes foram questionados acerca dos ativos em que menos investem, mais investem e nos quais pretendem investir futuramente, nos próximos três anos. Entre as opçóes de ativos disponibilizados para escolha em ambas as questôes, estavam as seguintes alternativas: poupança, capitalizaçóes, títulos públicos de renda fixa, títulos privados de renda fixa e açôes. 
As alternativas escolhidas pelos investidores pesquisados foram sintetizadas conforme apresentado na Tabela 1 .

Tabela 1 - Ativos escolhidos pelos investidores pesquisados

\begin{tabular}{|c|c|c|c|}
\hline ATIVOS & $\begin{array}{c}\text { MENOS } \\
\text { INVESTEM }\end{array}$ & $\begin{array}{c}\text { MAIS } \\
\text { INVESTEM }\end{array}$ & $\begin{array}{c}\text { PRETENDE } \\
\text { INVESTIR }\end{array}$ \\
\hline AÇÓES & $49 \%$ & $6 \%$ & $10 \%$ \\
\hline TÍTULOS PÚBLICOS DE RENDA FIXA & $18 \%$ & $8 \%$ & $18 \%$ \\
\hline $\begin{array}{l}\text { TÍTULOS PRIVADOS DE RENDA } \\
\text { FIXA }\end{array}$ & $3 \%$ & $59 \%$ & $57 \%$ \\
\hline CAPITALIZAÇÓES & $21 \%$ & $3 \%$ & $4 \%$ \\
\hline POUPANÇA & $9 \%$ & $24 \%$ & $11 \%$ \\
\hline TOTAL & $100 \%$ & $100 \%$ & $100 \%$ \\
\hline
\end{tabular}

Fonte: elaborado pelos autores (2015).

É possível perceber a preferência existente entre os investidores pesquisados pelos ativos privados de renda fixa, opção escolhida por $59 \%$ dos entrevistados como sendo o ativo em que preferem investir atualmente, e por $57 \%$ dos investidores como o ativo em que pretendem investir futuramente. Por sua vez, os ativos de renda variável, no caso as açōes, foram citados por apenas $6 \%$ dos investidores como o ativo em que mais investem e por apenas $10 \%$ como o ativo em que pretendem investir.

Essa preferência dos investidores por ativos caracterizados como sendo de renda fixa, pode ser visualizada também no estudo de Landvoigt (2007), no qual mais de $40 \%$ da amostra pesquisada afirma investir em fundo DI, classificado como um investimento de renda fixa, e outros $27 \%$ da amostra dizem investir em fundos de renda fixa. Em ambas as pesquisas, a possível explicação para tal fenômeno pode estar relacionado ao fato de os entrevistados considerarem os ativos de renda fixa o investimento mais rentável e com menor risco.

Quando questionados em relação aos investimentos considerados mais arriscados, 90\% dos investidores entrevistados disseram acreditar serem as açóes o ativo de maior risco. Portanto este investimento, mesmo sendo considerado por $27 \%$ dos entrevistados como um dos ativos mais rentáveis, não seria a opção escolhida pelos pesquisados. Essa percepção apresenta influências da heurística da representatividade, ou seja, do julgamento baseado em estereótipos pré-concebidos.

De acordo com Tversky e Kahneman (1974), isso ocorre porque em grande parte das vezes, estes julgamentos são frutos de informaçóes escassas e de baixa confiabilidade, náo resultando, portanto, de estudos acerca do tema. Ao serem questionados a respeito do nível de conhecimento que possuem sobre investimentos financeiros, $38 \%$ dos investidores entrevistados afirmaram que pesquisam sobre o assunto, porém, preferem tomar uma decisão de investimento somente após serem orientados por uma profissional, demonstrando certo grau de insegurança e pouco conhecimento proveniente de estudos aprofundados no tema. 
Um resultado similar é encontrado novamente na pesquisa de Landvoigt (2007), onde mais de $38 \%$ dos entrevistados afirmam não se sentir seguros para tomar uma decisão sem orientaçáo profissional - demonstrando, portanto, pouco domínio acerca do assunto entretanto avaliando como ativo mais arriscado as açóes (72\% dos entrevistados).

É possível perceber ainda a influência da heurística da disponibilidade nas decisóes tomadas pelos investidores pesquisados quando estes associam um conjunto de informaçóes que lhes são familiares e conhecidas. Este comportamento é identificado com maior clareza no momento em que $62 \%$ dos investidores entrevistados afirmam diversificar seus investimentos unicamente por acreditar que essa seja a melhor estratégia para se evitar o risco. Esta opiniáo dos investidores é resultado do conhecimento tácito elaborado por meio do que Tversky e Kahneman (1974) chamam de operaçôes mentais de recordação, construção e associação de informaçôes e situaçôes vivenciadas anteriormente.

Em relação à expectativa de retorno dos investidores, $46 \%$ dos entrevistados consideram como sendo uma situação favorável obter $20 \%$ de retorno em seus investimentos e, em um cenário desfavorável no mínimo manter seu capital. Quando somado ao fato de que $44 \%$ dos entrevistados dizem preferir investir em produtos de baixo risco com pouca chance de perda, fica evidente o fator comportamental chamado de aversão à perda, no qual, segundo Assaf Neto (2010), a dor da perda é sentida em maior peso se comparada à satisfação gerada pelo ganho.

Em caso de redução no valor de suas aplicações $43 \%$ dos investidores tomariam a decisão de não sair imediatamente do investimento buscando primeiramente planejar melhor sua estratégia. Essa decisão, conforme Halfeld e Torres (2001) demonstram que diante da possibilidade da perda geralmente as pessoas assumem riscos somente para tentar evitá-la.

A partir das preferências dos investidores por diferentes situaçóes hipotéticas de ganho e perda, é possível então classificá-los como sendo de perfil conservador, moderado ou arrojado, conforme exposto no Gráfico 1.

Gráfico 1 - Classificação por perfil de acordo com as preferências de ganhos e perdas

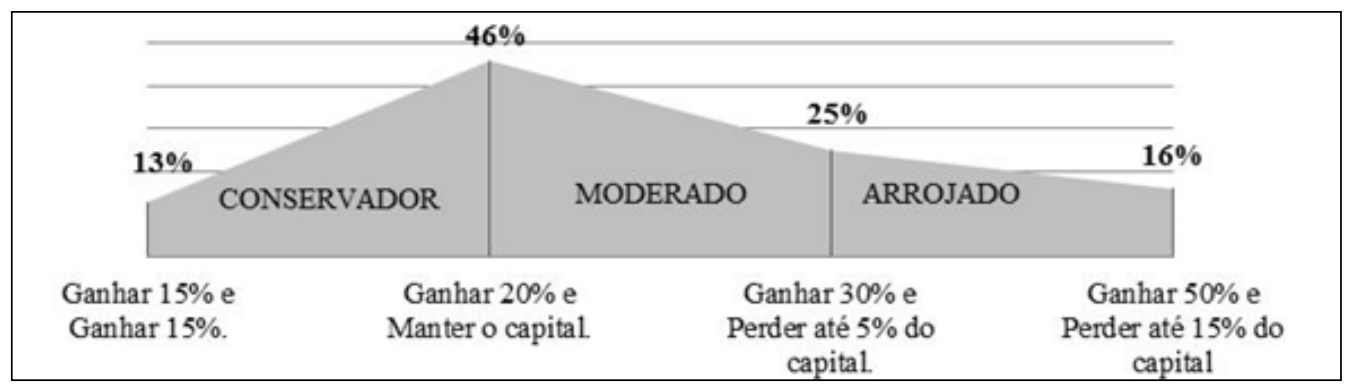

Fonte: elaborado pelos autores (2015).

É possível notar que $13 \%$ dos investidores pesquisados preferem situaçóes onde teriam apenas ganhos financeiros de $15 \%$. O maior grupo de entrevistados (46\%) prefere uma situação de ganho hipotética de $20 \%$ e em caso de situação de perda, no mínimo 
manter seu capital. Portanto, essa parte da amostra apresenta um perfil conservador, rejeitando situaçóes de perda de seus recursos financeiros. Por sua vez, $25 \%$ dos investidores apresentam um comportamento considerado moderado, aceitando uma perda de até, no máximo, 5\% de seu capital. Percebe-se ainda que os investidores de perfil arrojado (16\%), portanto, que aceitam uma perda mais elevada de seu capital, representam uma parcela pequena da amostra pesquisada.

Esta classificação por perfil realizada por meio da preferência dos investidores pesquisados é confirmada quando confrontada com a percepção que os próprios investidores pesquisados possuem de seu perfil. Entre os entrevistados, $56 \%$ dizem ser de perfil conservador, $41 \%$ de perfil moderado, e apenas 3\% apresentam-se como de perfil arrojado. Mas os mesmos investidores, quando questionados acerca da finalidade de seus investimentos, alegaram em maior número (28\%) buscar a elevação de seu capital. Este grupo que visa à elevação de seu capital é composto tanto por investidores que se classificam como sendo de perfil conservador, assim como os de perfil moderado.

Bodie, Kane e Marcus (2000) também apontam que os investidores que possuem uma maior tolerância ao risco, portanto de perfil moderado ou arrojado, buscam retornos maiores. Moraes (2011) corrobora que é da natureza do investidor de perfil moderado buscar investimentos que possam gerar retornos a médio e longo prazo.

Porém, o grupo de investidores de perfil conservador que deseja elevar seu capital constitui uma exceção à regra, o que contraria o conhecimento até então vigente, o qual preconiza que estes investidores deveriam buscar, exclusivamente, a proteção do seu capital. Uma hipótese passível de uma maior investigação, diz respeito ao caso desses investidores, os quais se classificam como sendo de perfil conservador, serem na verdade investidores de perfil moderado, induzidos por circunstâncias do mercado ou até mesmo particulares, a reduzirem a sua aceitação ao risco, adquirindo assim um comportamento conservador.

Esta hipótese corrobora o exposto por Damodaran (2006), que defende a ideia de que fatores e circunstâncias do mercado afetam o nível de aceitação ao risco dos indivíduos. Essa situação fica ainda mais evidente quando confrontados os investimentos escolhidos pelos entrevistados com o perfil que os mesmos julgam possuir, como apresentado no Gráfico 2. 
Gráfico 2 - Investimentos e perfil dos investidores

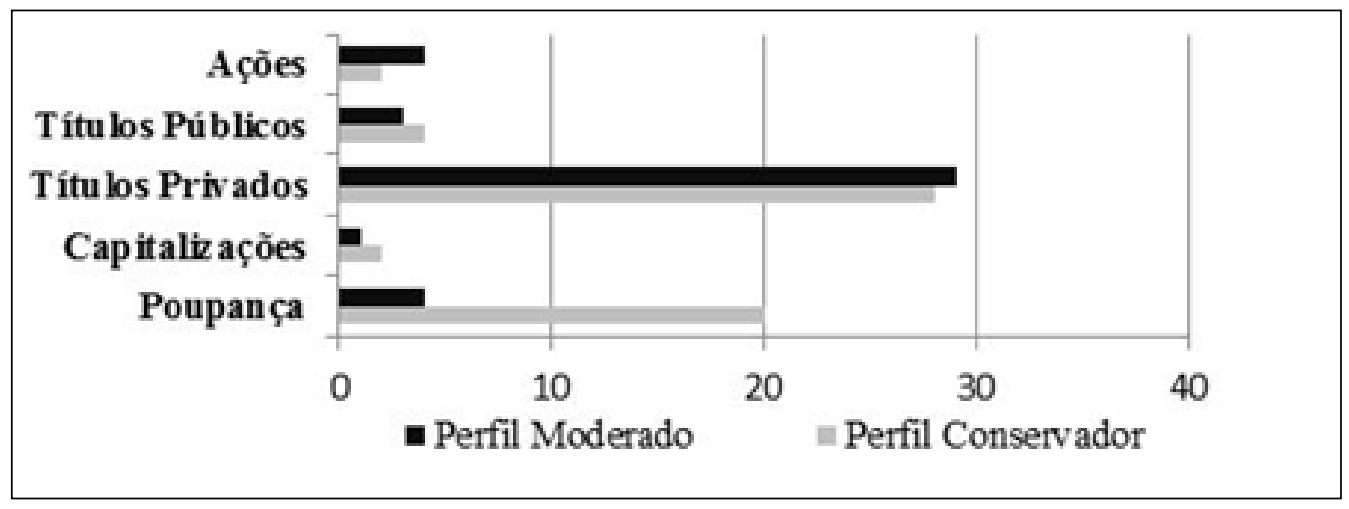

Fonte: Elaborado pelos autores (2015).

Os investidores que se classificam como sendo de perfil conservador investem, em maior número (28\%), nos títulos privados e em segundo lugar na poupança, optando, portanto, pelos ativos de renda fixa. Por sua vez, os investidores que acreditam possuir um perfil moderado, investem em grande parte (29\%) nos títulos privados, ativo escolhido, portanto, pela maior parcela dos investidores entrevistados.

Estes investidores de perfil conservador ao optarem por investir em títulos privados contrariam a análise apresentada por Moraes (2011), onde o autor ressalta que o investidor conservador não aceita correr riscos para ganhar mais e procura sempre a segurança. Neste caso, parte dos investidores que se consideram conservadores realizaram escolhas semelhantes ao dos investidores de perfil moderado, investindo em ativos com relativo grau de risco, entretanto como esclarece Póvoa (2012), nem sempre o fato de o investidor parecer ser mais arrojado significa que isso seja uma realidade.

$\mathrm{O}$ autor destaca que outros fatores exercem grande influência nas atitudes dos investidores, sendo eles a idade, a renda e o perfil. Essas são algumas das dimensōes básicas capazes de auxiliar, de forma objetiva, na mensuração do nível de aversão a risco dos investidores.

Investidores que não desfrutam de condições financeiras favoráveis, tendem, naturalmente, a se expor menos a situaçóes de risco. Por outro lado, investidores com uma situação mais confortável financeiramente, que possuem uma margem de manobra maior, tendem a arriscar mais, uma vez que eventuais prejuízos afetarão os recursos excedentes e não os básicos.

A fim de identificar o impacto que fatores ligados a questôes financeiras pessoais, ao conhecimento acerca do tema e à experiência no ramo exercem nas decisóes tomadas pelos investidores pesquisados, foi averiguado em quais ativos os 29 investidores, que possuem renda superior a $\mathrm{R} \$ 10.000,00$, investem. Dentre esse grupo de investidores, $59 \%$ escolheram investir em títulos privados de renda fixa.

Acerca da faixa etária dos investidores entrevistados, a maior parte dos mesmos encontra-se dividida, quase que igualmente, entre dois grupos, a saber, os com mais de 50 
anos de idade - os quais correspondem a 33\% da amostra pesquisada - e os investidores com idade entre 31 e 40 anos, que representam 34\% da amostra. No grupo de investidores com idade acima dos 50 anos, 39\% investem com a finalidade de constituir uma reserva para a aposentadoria e 36\% buscam a proteção de seu capital. Portanto, 75\% dos investidores com mais de 50 anos pretendem, basicamente, guardar seus recursos. Por sua vez, o grupo de investidores, com idades entre 31 e 40 anos, busca em maior número (32\%) a elevação de seu capital.

Em relação aos investidores de gêneros diferentes foi realizado o cruzamento entre a finalidade dos investimentos escolhidos por estes investidores. Quando questionados acerca da finalidade de seus investimentos, $30 \%$ dos investidores do gênero masculino buscam elevar seu capital, seguidos por $27 \%$ que investem com a intenção de comprar um bem. Entretanto, a maior parcela de investidores do gênero feminino (35\%) disse aplicar seus recursos com a finalidade de construir uma reserva para sua aposentadoria. É possível perceber, portanto, que os investidores masculinos entrevistados, apresentam algumas escolhas relativamente mais ousadas que investidores do gênero feminino.

No que se refere à compilação dos dados gerais - obtidos por meio dos questionários respondidos - referentes aos aspectos: gênero, idade, estado civil, número de dependentes, nível de escolaridade e renda dos investidores pesquisados, permite-se que seja estabelecido um perfil predominante dos mesmos, conforme apresentado no Quadro 1.

Quadro 1 - Perfil predominante dos investidores pesquisados

\begin{tabular}{|c|c|c|}
\hline Gênero & Masculino & $\mathbf{5 5 \%}$ \\
\hline Idade & Entre 31 e 40 anos & $\mathbf{3 4 \%}$ \\
\hline Estado Civil & Casado & $\mathbf{6 4 \%}$ \\
\hline Dependentes & De 1 a 3. & $\mathbf{5 1 \%}$ \\
\hline Escolaridade & Superior completo & $\mathbf{3 7 \%}$ \\
\hline Renda & De R $\$ 5.000,00$ a R $\$ 10.000,00$ & $\mathbf{3 2 \%}$ \\
\hline
\end{tabular}

Fonte: elaborado pelos autores (2015).

Conclui-se, portanto, que o perfil predominante da amostra pesquisada é composto por investidores do gênero masculino, com idade entre 31 e 40 anos, casados, que possuem entre um e três dependentes, com nível superior completo e com uma renda entre $\mathrm{R} \$$ $5.000,00$ a $\mathrm{R} \$ 10.000,00$ reais.

\section{DISCUSSÓES E CONSIDERAÇÓES FINAIS}

A partir da análise dos dados obtidos por meio desta pesquisa constatou-se, primeiramente, que o comportamento apresentado pelos investidores pesquisados e os fatores emocionais e psicológicos ligados a estes comportamentos estão em sintonia com vários dos estudos elaborados anteriormente e apresentados no referencial teórico. 
Dentre os inúmeros trabalhos e autores citados, é importante ressaltar o trabalho de Tversky e Kahneman (1979), os quais foram os precursores neste campo de estudo, ao utilizar diversos conceitos da psicologia na análise da tomada de decisão e do comportamento de agentes financeiros. Os resultados obtidos ao longo desta pesquisa corroboram com diversas teorias elaboradas por esses autores, sendo a mais notável delas a aversão ao risco analisada na teoria da perspectiva e identificada nos investidores pesquisados.

Também, faz-se importante mencionar a contribuição do trabalho de pesquisa de Macedo Junior (2003), por ser este um dos pioneiros no estudo das finanças comportamentais no Brasil, investigando o tema quando pouco se discutia sua relevância em âmbito nacional. Macedo Junior, posteriormente, ao publicar um livro em conjunto com pesquisadores da área da psicologia - Kolinsky e Morais - investiga diversos fatores comportamentais que agem sobre os indivíduos durante seu processo de tomada de decisão, dentre os quais vários são apresentados pelos entrevistados neste trabalho.

É possível concluir ainda que a amostra pesquisada é composta em grande parte por investidores de perfil conservador, os quais apresentam diversas características em comum, como o medo da perda financeira, a aversáo ao risco e a preferência por títulos de renda fixa. Entretanto, chama a atenção o fato de alguns investidores que se classificam como sendo de perfil conservador, apresentarem um comportamento típico de perfil moderado, e que buscam futuramente a elevação de seu capital.

Este fato pode estar ligado ao momento em que a pesquisa foi realizada, uma vez que o mercado apresentava inúmeras oscilaçóes ocasionadas por incertezas políticas e econômicas, tanto a nível estadual quanto nacional. Visto que cenários desfavoráveis podem afetar a aceitação a produtos considerados arriscados e acentuar o conservadorismo, é possível que investidores de perfil moderado tenham adquirido um comportamento conservador por forças das circunstâncias, mesmo que desejem ainda alcançar objetivos considerados mais audaciosos.

Outra possível razão para esta constatação está ligada ao fato de a amostra pesquisada não ter sido constituída com base em critérios como área de formação ou profissão, sendo possível então que a amostra seja composta por investidores financeiros com diferentes profissóes e áreas de atuação. Portanto, o pouco domínio referente ao assunto pode levar ao medo do desconhecido ou pouco conhecido, provocando entáo um comportamento de caráter mais conservador e realçando características como o medo da perda financeira.

Deve ser destacado o fato de a presente pesquisa não possuir uma amostragem uniforme, com o mesmo número de investidores entrevistados entre as diferentes instituiçóes financeiras pesquisadas, impossibilitando assim, a realização de uma comparação mais aprofundada entre o comportamento e o perfil dos entrevistados de diferentes instituiçóes.

Ainda assim, os autores buscaram, através dessa pesquisa, contribuir com a disseminação desse campo de estudo na academia e além dela, colaborando, mesmo que minimamente, com os futuros pesquisadores e trabalhos que venham a ser elaborados acerca do tema. Com respeito às sugestóes para as futuras pesquisas a serem realizadas acerca do tema, estas devem se ater sim ao conteúdo teórico referente ao assunto, porém é de suma 
importância que busquem trazer novos conselhos e conceitos aos profissionais do ramo, aproximando cada vez mais a teoria e a prática.

Por se tratar de um tema complexo, que envolve duas escolas de pensamentos diferentes - a comportamental e a financeira - porém, que estão totalmente interligadas, uma vez que os agentes que operam no mercado financeiro são humanos que apresentam diferentes reaçóes, emoções, habilidades e competências, é de absoluta importância que os pesquisadores que venham a explorar o tema estejam abertos a buscar e a se aprofundar em campos de estudo e autores de outras áreas, que até algum tempo não eram levadas em consideração quando se pensava em finanças, como, por exemplo, a psicologia.

\section{REFERÊNCIAS}

ANACHE, Marcelo de Carvalho Azevedo; LAURENCEL, Luiz da Costa. Finanças Comportamentais: uma avaliação crítica da moderna teoria de finanças. Revista CADE, vol. 12, n.1, p. 83-120, 2013. Disponível em: http://editorarevistas.mackenzie.br/index. php/cade/article/view/6331>. Acesso em: $10 \mathrm{dez} .2015$.

ASSAF NETO, Alexandre. Finanças Corporativas e Valor. 5. ed. São Paulo: Atlas, 2010.

BODIE, Zvi; KANE, Alex; MARCUS, Alan. Fundamentos de Investimentos. 3. ed. Porto Alegre: Bookman, 2000.

COLLIS, Jill; HUSSEY, Roger. Pesquisa em Administração: um guia prático para alunos de graduação e pós-graduação. 2. ed. Porto Alegre: Bookman, 2005.

CROSON, Rachel; GNEEZY, Ury. Gender Differences in Preferences. Journal of Economic Literature, vol. 42, n. 2, p. 1-27, 2009. Disponível em: <http://rady.ucsd.edu/ faculty/directory/gneezy/pub/docs/gender-differences-preference.pdf $>$. Acesso em: 03 jun. 2016.

DAMODARAN, Aswath. Mitos de investimentos. São Paulo: Financial Times - Prentice Hall, 2006.

HALFELD, Mauro; TORRES, Fábio de Freitas Leitão. Finanças Comportamentais: aplicações no contexto brasileiro. Revista de Administração - RAE, vol. 41, n.2, p. 64$71,2001$.

KAHNEMAN, Daniel. Rápido e devagar: duas formas de pensar. Rio de Janeiro: Objetiva, 2012.

LANDVOIGT, Deisiane Cristine. Estudo das Finanças Comportamentais: O caso dos investidores em uma agência bancária. 2007. 77f. Monografia (Graduação) Universidade Federal do Rio Grande do Sul, Porto Alegre, 2007. 


\section{LUCCHESI, Eduardo Pozzi. O Efeito Disposiçáo e suas Motivaçóes}

Comportamentais: Um estudo com base na atuação de gestores de fundos de investimento em ações. 2010. 192f. Tese (Doutorado) - Universidade de São Paulo, São Paulo, 2010. Disponível em: <http://www.teses.usp.br/teses/disponiveis/12/12139/tde26052010-114534/pt-br.php>. Acesso em: $11 \mathrm{dez} .2015$.

MACEDO JUNIOR, Jurandir Sell. Teoria do Prospecto: Uma investigação utilizando simulação de investimentos. 2003. 218f. Tese (Doutorado) - Universidade Federal de Santa Catarina, Florianópolis, 2003. Disponível em: <https://repositorio.ufsc.br/ bitstream/handle/123456789/85921/199597.pdf? sequence=1>. Acesso em: 10 dez. 2015.

MACEDO JUNIOR, Jurandir Sell; KOLINSKY, Régine; MORAIS, José Carlos Junça de. Finanças comportamentais: como o desejo, o poder, o dinheiro e as pessoas influenciam nossas decisões. São Paulo: Atlas, 2011.

MORAES, Carlos Eli Dutra. Investimentos financeiros: o comportamento do investidor e a diversificação dos ativos. 2011. 44f. Trabalho de conclusão de especialização (Especialização) - Universidade Federal do Rio Grande do Sul, Porto Alegre, 2011.

Disponível em: <http://hdl.handle.net/10183/77356>. Acesso em: 12 dez. 2015.

NIQUE, Walter; LADEIRA, Wagner. Pesquisa de Marketing: uma orientação para o mercado brasileiro. São Paulo: Atlas, 2014.

PÓVOA, Alexandre. Valuation: Como precificar açóes. 2. ed. Rio de Janeiro: Elsevier, 2012.

TVERSKY, Amos; KAHNEMAN, Daniel. Judgment Under Uncertainty: Heuristics and Biases. Science, New Series. v. 185, p. 1124 - 1131, 1974. Disponível em: <http://psiexp. ss.uci.edu/research/teaching/Tversky_Kahneman_1974.pdf>. Acesso em: 09 dez. 2015. 


\section{APÊNDICE - Questionário para os investidores}

A seguinte pesquisa faz parte da realização do Trabalho de Conclusão do Curso de Administração do aluno Arthur Gehrke Martins Andrade pelo Centro Universitário Metodista IPA, orientado pelo Professor Carlos Artur dos Santos Lencini e tem como objetivo o estudo das finanças comportamentais no que envolve a tomada de decisão dos investidores.

Havendo o interesse de entrar em contato com o pesquisador, este se coloca a disposição através do e-mail: arthur_gma@hotmail.com

Prezado (a) Investidor (a),

As questóes abaixo não possuem uma resposta certa ou errada, apenas a finalidade de conhecer e avaliar o comportamento do tomador de decisão frente a algumas situaçóes.

Desde já agradeço a sua participação.

1. Em qual produto de investimento você MENOS investe? (Favor marcar apenas 1 resposta).

a) ( ) Poupança

b) ( ) Capitalizações

c) ( ) Títulos privados de renda fixa (CDB, debêntures, LCI)

d) ( ) Títulos públicos de renda fixa (Letras ou Notas do Tesouro)

e) ( ) Ações

2. Em qual produto de investimento você MAIS investe? (Favor marcar apenas 1 resposta).

a) ( ) Poupança

b) ( ) Capitalizaçóes

c) ( ) Títulos privados de renda fixa (CDB, debêntures, LCI)

d) ( ) Títulos públicos de renda fixa (Letras ou Notas do Tesouro)

e) ( ) Ações

3. Em qual produto de investimento você PRETENDE investir (em um período de 1 a 3 anos)? (Favor marcar apenas 1 resposta).
a) ( ) Poupança
b) ( ) Capitalizaçóes
c) ( ) Títulos privados de renda fixa
(CDB, debêntures, LCI)
d) ( ) Títulos públicos de renda fixa (Letras ou Notas do Tesouro)
e) ( ) Ações

\section{CASO VOCÊ INVISTA EM MAIS DE UM ATIVO, RESPONDA À QUESTÁO 4:}

4. Porque você prefere diversificar seus investimentos? (Favor marcar apenas 1 resposta).

a) ( ) Pois acredito que é a melhor forma de evitar o risco.

b) ( ) Porque meu gerente me aconselhou a diversificar. 
c) ( ) Não sei, simplesmente decidi investir em um produto diferente.

d) ( ) Porque não estava gostando do meu outro investimento.

5. Para você qual investimento pode ser considerado mais rentável? (Favor marcar apenas 1 resposta).
a) ( ) Poupança
b) ( ) Capitalizaçóes
c) ( ) Títulos privados de renda fixa
(CDB, debêntures, LCI)
d) ( ) Títulos públicos de renda fixa
(Letras ou Notas do Tesouro)
e) ( ) Ações

6. Para você qual investimento pode ser considerado mais arriscado? (Favor marcar apenas 1 resposta).
a) ( ) Poupança
b) ( ) Capitalizaçôes
c) ( ) Títulos privados de renda fixa
(CDB, debêntures, LCI)
d) ( ) Títulos públicos de renda fixa
(Letras ou Notas do Tesouro)
e) ( ) Ações

7. Considerando uma situaçáo favorável e outra desfavorável, qual a alternativa hipotética que melhor atenderia a sua expectativa de retorno? (Favor marcar apenas 1 resposta).

a) ( ) Situação favorável: ganhar 15\% e desfavorável: ganhar $15 \%$.

b) ( ) Situação favorável: ganhar $20 \%$ e desfavorável: manter o capital.

c) ( ) Situação favorável: ganhar 30\% e desfavorável: perder até $5 \%$ do capital.

d) ( ) Situação favorável: ganhar 50\% e desfavorável: perder até $15 \%$ do capital.

8. Qual é a fonte de informaçáo que você considera mais relevante para tomada de decisáo de seus investimentos? (Favor marcar apenas 1 resposta).

a) ( ) Internet, Jornais, Revistas, Televisão

b) ( ) Profissionais do mercado financeiro

c) ( ) Intuição

d) ( ) Família / Amigos

e) ( ) Gerente / consultor do banco

9. Qual o seu nível de conhecimento sobre alternativas de investimentos financeiros? (Favor marcar apenas 1 resposta).

a) ( ) Não me sinto seguro para tomar decisóes sozinho, prefiro buscar orientaçóes financeiras em minha agência.

b) ( ) Tenho pesquisado sobre o assunto, mas prefiro tomar uma decisão após ser orientado em minha agência.

c) ( ) Não me sinto seguro para tomar decisões sozinho, prefiro buscar orientações financeiras externas, não em minha agência.

d) ( ) Entendo como funciona o mercado financeiro, portanto não preciso de orientaçóes de terceiros.

10. O que você faria se houvesse reduçáo no valor de seu investimento? (Favor marcar apenas 1 resposta). 

a) ( ) Sairia do investimento imediatamente.
b) ( ) Tiraria uma parte do investimento.
c) ( ) Não sairia imediatamente e planejaria melhor minha estratégia de investimento.
d) ( ) Aceitaria perdas a curto prazo com expectativas de ganhos a longo prazo.

11. Das alternativas abaixo, qual melhor representa a sua preferência em relaçáo aos seus investimentos? (Favor marcar apenas 1 resposta).

a) ( ) Investir em produtos de baixo risco, com pouca chance de perda, com a finalidade de preservar meu capital.

b) ( ) Investir a maior parte em produtos de baixo risco, o restante em produtos de maior risco, visando o crescimento moderado de meu capital.

c) ( ) Investir partes iguais em produtos de baixo e de maior risco, visando o crescimento de meu capital.

d) ( ) Investir a maior parte em produtos de maior risco, o restante em produtos de baixo risco, visando um grande crescimento do meu capital.

12. Para você, qual é a finalidade de seus investimentos? (Favor marcar apenas 1 resposta).

a) ( ) Compra de um bem.

b) ( ) Elevação do capital.

c) ( ) Reserva para aposentadoria.

d) ( ) Proteção do capital.

13. Entre as opçóes abaixo, em sua opinião, qual melhor descreve o seu perfil de investidor? (Favor marcar apenas 1 resposta).
a) ( ) Conservador.
b) ( ) Moderado
c) ( ) Arrojado

14. Gênero:
a) ( ) Masculino
b) ( ) Feminino

15. Idade:
a) ( ) Menos de 20 anos.
b) ( ) Entre 21 e 30 anos.
c) ( ) Entre 31 e 40 anos.
d) ( ) De 41 a 50 anos.
e) ( ) Mais de 50 anos.

16. Estado Civil:
a) ( ) Solteiro.
b) ( ) Casado.
c) ( ) Divorciado.

17. Número de dependentes:
a) ( ) Nenhum.
b) ( ) De 1 a 3 .
c) ( ) Mais de 3 . 
18. Escolaridade:
a) ( ) Ensino médio incompleto.
b) ( ) Ensino médio completo.
c) ( ) Superior incompleto.
d) ( ) Superior completo.
e) ( ) Pós-graduação incompleta.
f) ( ) Pós-graduação completa.

19. Qual a sua renda? Caso náo tenha, informar sua renda familiar.
a) ( ) Até R\$1.000,00.
b) ( ) $\mathrm{R} \$ 1.001,00$ a $\mathrm{R} \$ 3.000,00$
c) ( ) $R \$ 3.001,00$ a $R \$ 5.000,00$
d) ( ) $\mathrm{R} \$ 5.001,00$ a $\mathrm{R} \$ 10.000,00$
e) ( ) Acima de R $\$ 10.000,00$ 